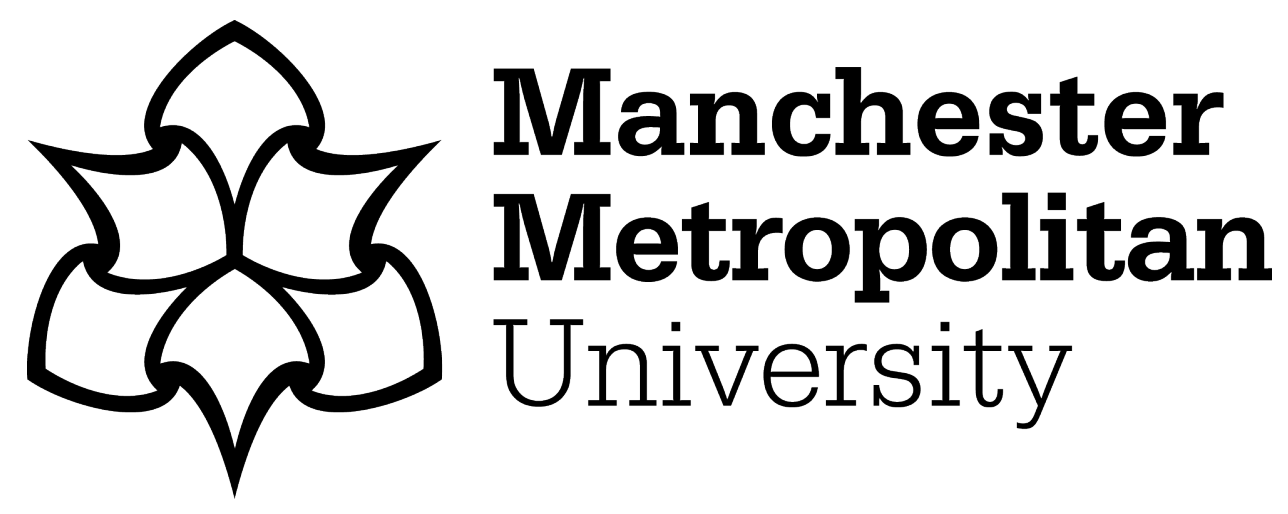

Parry, SL and Weatherhead, S (2014) A critical review of qualitative research into the experiences of young adults leaving foster care service. Journal of Children's Services, 9 (4). ISSN 1746-6660

Downloaded from: https://e-space.mmu.ac.uk/847/

Version: Accepted Version

Publisher: Emerald

DOI: https://doi.org/10.1108/JCS-04-2014-0022

Please cite the published version 


\title{
A critical review of qualitative research into the experiences of young adults leaving foster care services
}

\author{
Sarah Parry and Stephen Weatherhead
}

\begin{abstract}
Purpose - Due to the emergence of rich personal narratives within recent research, the purpose of this paper is to review and to explore the experience of transition from care and consider how these accounts can inform care services.

Design/methodology/approach - This meta-synthesis follows from several quantitative and mixed method reviews examining how young people experience aging out of the care system.

Findings - Three themes emerged from an inductive analysis: navigation and resilience - an interrelated process; the psychological impact of survival; and complex relationship.

Research limitations/implications - The findings of a meta-synthesis should not be over generalised and are at least partially influenced by the author's epistemological assumptions (Dixon-Woods et al., 2006). However, a synthesis of this topic has the potential to provide greater insight into how transition can be experienced through the reconceptualising of the personal experiences across the studies reviewed (Erwin et al., 2011).

Practical implications - This synthesis discusses the themes; their relationship to existing research and policies, and suggestions for further exploration. The experience of transition is considered critically in terms of its often traumatic nature for the young person aging out of care but also the ways in which the experience itself can build essential resiliencies.

Social implications - Reflections for clinical practice are discussed with importance placed upon systemic working, accommodating likely challenges and considering appropriate therapeutic approaches for the client group and their systems.

Originality/value - No review thus far has qualitatively examined the narratives told by the young people emerging from care and how these narratives have been interpreted by the researchers who sought them (Hyde and Kammerer, 2009).

Keywords Transition, Resilience, Care services, Attachment, Clinical psychology, Young adults

Paper type Research paper

\section{Introduction}

In 2013 there were approximately 92,000 children cared for by local authorities in the UK. Over half of these young people entered care due to abuse or neglect. The number of young people entering the care system has risen by 11,413 between 2008 and 2013 (NSPCC, 2014). The cost of care provisions in 2012 was £2.22 billion (Harker, 2012). Young people in care can be at greater risk of developing mental illness (Golding, 2003; Mullan et al., 2007; Stein, 2006), particularly "clinical levels of depression, anger, post-traumatic stress, and dissociation" (Collin-Vézina et al., 2011, p. 585). Adversities faced have been found to impact their "self-esteem, self-efficacy and capacity to cope with developmental challenges" (Schofield and Beek, 2005, p. 1283).

The parenting role assumed by the state could last beyond childhood in terms of the provisions young people may need once they leave care (Blades et al. , 2011). It has been suggested there
\end{abstract}


are long-term implications of life in care on educational outcome, offending behaviour and homelessness (Jackson and Simon, 2005; Tyler, 2006). One in four of those who transition out of care are subject to physical and sexual abuse within eighteen months of leaving care (Courtney et al., 2001) and continue to be at an elevated risk of social exclusion and loneliness in adulthood (Jackson and Cameron, 2012; Stein, 2006).

The Who Cares Trust (2012) suggests the care system can leave a young person "alone in the wilds of adult life". Difficulties faced in the care system can lead young people into a "double transition" (Dima and Skehill, 2011, p. 2537) as they experience a simultaneous and sudden transition from care as a child into the community as an independent adult. This acceleration to adulthood and independence leaves little psychological opportunity to adjust to significant life changes over time (Stein, 2006). Additionally, some young people still fall through the gaps between services (Department of Health, 2007). Whilst the problems are well researched, less is understood about the resilience that can enable individuals to overcome these adversities (Walsh et al., 2010).

Windle (1999), cited in Lewis et al. (2011, p. 3), identifies resilience as "the successful adaptation to life tasks in the face of social disadvantage or highly adverse conditions" (p. 163). In order for one to develop resilience a number of skills must be learnt first, such as helpful coping skills and developing social supports (Layne et al., 2007). Further, resilience goes beyond surviving challenges because it requires one to fully experience and reflect upon challenges (Harvey and Delfabbro, 2004). Gilligan (2000) has highlighted emotional resilience and practical skills as essential components of a positive transition.

Positive attachments can play a key part in the development of these features. Sadly, for many of the children who enter the care system as a result of neglect and abuse, their attachments and psychosocial functioning have already been damaged (Stovall-McClough and Dozier, 2004). These authors highlight the importance of early preventative interventions when a foster placement begins, rather than waiting until difficulties arise. Golding (2003) suggests that the early experiences of looked after children play a fundamental role in how they relate to their subsequent carers, which may also impact on their ability to develop other social supports, emotional resilience and helpful coping strategies.

\section{Rationale for the current review}

NICE guidelines for looked after children recognise that transition out of care can be "traumatic" (2010, p. 9) and recommend that the mental health of looked after children is considered as part of the young person's "complex needs" (p. 62). However, there is little explicit national guidance as to how looked after children in the UK can be served through psychological services.

A number of qualitative reviews have explored the transition from care. For example Spencer et al. (2010) emphasised the need for services to provide systemic support for care leavers. Young people transitioning from care often experience difficulties simultaneously, which impact upon their global ability to cope (Stein, 2006).

Stone (2007) reviewed child maltreatment and foster care experiences presenting conceptual and methodological considerations for policy review and future research. Hayes (2013) critically reviewed existing legislation and policy relating to transition. She found in support of other literature that educational success, social support networks, placement stability, good mental health and preparation for transition are all important in managing the process well. Importantly, she highlighted that the choices a young person makes through transition in terms of life course are particularly crucial due to the limited follow-on resources available throughout their 20s if they do not remain in education. In a sense, there is no going back for these young people, which in a society where so many value parental supports throughout their 20 s puts foster youth at an even greater disadvantage.

No review thus far has qualitatively examined the narratives told by the young people emerging from care and how these have been interpreted by the researchers who sought them (Hyde and Kammerer, 2009). 


\section{Aims of the review}

Jackson and MacParlin (2006, p. 90) suggested looked after children are "disproportionately likely" to be referred to a psychologist and as such it is crucial to understand the processes that precede the referrals. Ideally, clinical psychologists can fulfil individual therapeutic roles as well as provide supportive consultancy to carers and staff teams (Biehal et al., 2012). These roles can be underpinned by the knowledge of how a young person might develop within the care system and the bi-directional dynamic nature of how the care system and young person can affect each other. Due to the emergence of rich personal narratives within recent research, a review can now be conducted to explore the experience of transition from a psychosocial perspective.

The findings of a meta-synthesis should not be over generalised and are at least partially influenced by the author's epistemological assumptions (Dixon-Woods et al., 2006). Additionally, with few qualitative studies emerging from the UK, the results of this synthesis provide an array of perspectives rather than a direct depiction of care leavers in the UK today. However, a synthesis of this nature has the potential to provide greater insight into how transition can be experienced through the reconceptualising of the personal experiences across the studies reviewed (Erwin et al., 2011). It is hoped the individual experiences explored throughout this synthesis may indicate recommendations for psychological support.

\section{Method}

Systematic literature searches were undertaken of OneSearch, MetaLib, PubMed, The Cochrane Library and PsychSpider, between September 2012 and December 2012 (Appendix). A qualitative approach was taken to the analysis as the aim of the study was to develop a deeper understanding from personal accounts about the experiences of young people aging out of care. This deeper understanding can hopefully "augment existing theory as well as prompt insight" (Hodges, 2011, p. 91), an important next step in using personal experiences to further guide mental health policy and practice.

\section{Quality appraisal}

There remains much debate around whether quality assurance measures should be applied to qualitative research for review purposes (Thomas and Harden, 2008). However, in order to source the most relevant stories of transition this review only included studies that collected qualitative data through individual face-to-face interviews with participants who had aged out of care or who were currently in the process. Many of the participants had experienced multiple moves between foster homes and children's homes. As such, the terms care and foster youth are used to encapsulate the range of placements they experienced throughout childhood. The selected studies were checked against the Critical Appraisal Skills Programme (2010) in order to appraise rather than eliminate studies as outlined in Table I.

\section{Data analysis}

Articles were included if they provided a qualitative analysis of personal stories of care to community transitions. There are some demographic and epistemological differences amongst the articles. For example, some sought evidence of conceptual structures such as self-reliance (Samuels and Pryce, 2008) and others explored perspectives on aspects of care and transition such as education (Del Quest et al., 2012; Hyde and Kammerer, 2009) or adjustment to life thereafter (Jones, 2011; Perez and Romo, 2011; Sala-Roca et al., 2012). This heterogeneity, whilst presenting challenges, does broaden the conceptual pool from which the review draws (Thomas and Harden, 2008) and increases generalisaibility of the findings.

Once the studies were transposed into NVivo9, a computerised qualitative analysis software package, an inductive approach was taken to the thematic analysis. A line by line approach was taken to the analysis in order to interpret each element of the studies into a unifying coding 


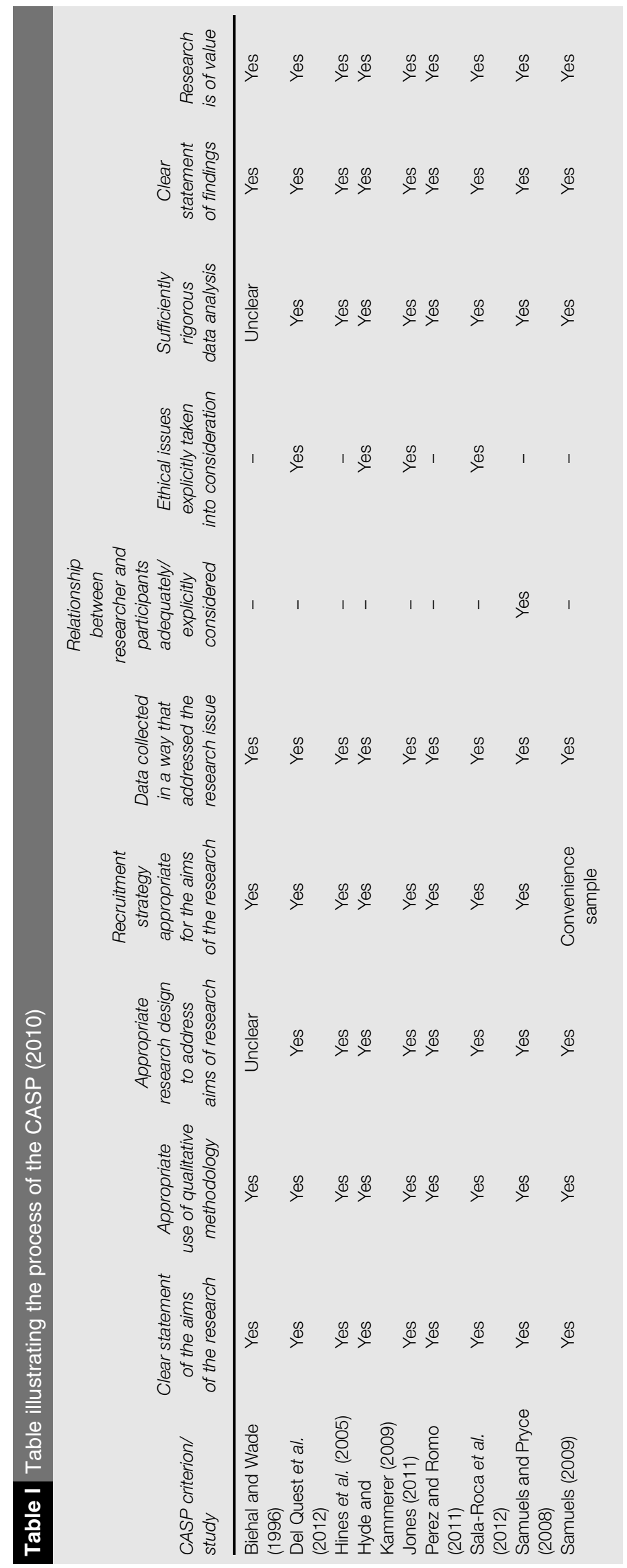


system that built the meta-synthesis. In order to check consistency, the first study to be coded was reviewed at the end of the coding process (Thomas and Harden, 2008).

The inductive thematic analysis yielded 670 codes, which were then grouped together into 192 themes. Totally, 28 descriptive themes were established, based upon their implications for participants. These 28 themes then formed four superordinate themes: complex relationships, the psychological impact of surviving, navigators and resilience. These final two themes were amalgamated as a key message through the participants' accounts was that resilience and navigational skills aided success symbiotically. The codes within the themes were counted in order to check that each theme was proportionate (Table II).

\section{Analytic approach}

As conceptualised by Gomersall et al. (2011), a three level approach was taken to interpreting the findings of the current synthesis. First, the interview data in the nine articles reviewed provided individual accounts of transitioning out of care. Their constructs were then interpreted by the researchers who undertook the original research who made connections through the data. Finally, a line by line approach was taken to the analysis that formed the translation aspect

Table II Characteristics of the identified literature

\begin{tabular}{|c|c|c|c|c|}
\hline Study & Participants & Analysis & Findings & Limitations \\
\hline $\begin{array}{l}\text { Biehal and Wade } \\
\text { (1996) (UK) }\end{array}$ & $\begin{array}{l}74 \text { participants aged } \\
16-19 \text { years }\end{array}$ & $\begin{array}{l}\text { Thematic } \\
\text { analysis }\end{array}$ & $\begin{array}{l}\text { Themes around transition as a } \\
\text { process }\end{array}$ & $\begin{array}{l}\text { Little methodological information } \\
\text { available such as who collected the data } \\
\text { or nature of interviews. Ethics not } \\
\text { discussed }\end{array}$ \\
\hline $\begin{array}{l}\text { Del Quest et al. } \\
\text { (2012) (USA) }\end{array}$ & $\begin{array}{l}7 \text { participants aged } \\
15-18 \text { years. } 3 \text { male } \\
\text { and } 4 \text { female }\end{array}$ & $\begin{array}{l}\text { Constant } \\
\text { comparative } \\
\text { analysis }\end{array}$ & $\begin{array}{l}\text { Personal narratives re-told and } \\
\text { themes around resilience, } \\
\text { support and achievement }\end{array}$ & $\begin{array}{l}\text { Participants were received specialist } \\
\text { educational support. Ethics not } \\
\text { discussed }\end{array}$ \\
\hline $\begin{array}{l}\text { Hines et al. (2005) } \\
\text { (USA) }\end{array}$ & $\begin{array}{l}14 \text { foster youth, } 4 \text { men } \\
\text { and } 10 \text { women aged } \\
19 \text { to } 35 \text { years old. All } \\
\text { placed in care due to } \\
\text { abuse at birth home }\end{array}$ & $\begin{array}{l}\text { Grounded theory } \\
\text { and extended } \\
\text { case method }\end{array}$ & $\begin{array}{l}\text { A process model of pathways to } \\
\text { resilience for foster youth }\end{array}$ & $\begin{array}{l}\text { Only included existing university students } \\
\text { previously in care. Ethics not discussed. } \\
\text { Paid } \$ 20 \text { to participate }\end{array}$ \\
\hline $\begin{array}{l}\text { Hyde and } \\
\text { Kammerer (2009) } \\
\text { (USA) }\end{array}$ & $\begin{array}{l}20 \text { participants aged } \\
16-19 \text { years }\end{array}$ & $\begin{array}{l}\text { Thematic } \\
\text { analysis }\end{array}$ & $\begin{array}{l}\text { Themes regarding the } \\
\text { participants' perspectives of } \\
\text { their care }\end{array}$ & $\begin{array}{l}\$ 25 \text { gift certificate provided. Unclear as to } \\
\text { whether participants were in state care } \\
\text { before the age of sixteen. Participants still } \\
\text { in state care when participated; may have } \\
\text { affected their answers to questions. } \\
\text { Ethics not discussed }\end{array}$ \\
\hline $\begin{array}{l}\text { Jones (2011) } \\
\text { (USA) }\end{array}$ & $\begin{array}{l}42 \text { participants age } \\
16-19 \text { years }\end{array}$ & $\begin{array}{l}\text { Comparative } \\
\text { thematic analysis }\end{array}$ & $\begin{array}{l}\text { Themes around connections } \\
\text { and perceptions }\end{array}$ & $\begin{array}{l}\text { No participants with severe mental health } \\
\text { difficulties. All motivated to succeed } \\
\text { academically. Ethics not discussed. } \\
\text { Findings overlaid to predetermined } \\
\text { conceptual framework }\end{array}$ \\
\hline $\begin{array}{l}\text { Perez and Romo } \\
\text { (2011) (USA, } \\
\text { Latino foster } \\
\text { youth) }\end{array}$ & $\begin{array}{l}32 \text { participants aged } \\
18-22 \text { years. } 14 \text { male } \\
\text { and } 18 \text { female }\end{array}$ & $\begin{array}{l}\text { Inductive } \\
\text { thematic analysis }\end{array}$ & $\begin{array}{l}\text { Themes of reconnecting, social } \\
\text { networks and cultural } \\
\text { differences }\end{array}$ & $\begin{array}{l}\text { Different researchers conducted the } \\
\text { interviews although followed a schedule. } \\
\text { Ethics not discussed }\end{array}$ \\
\hline $\begin{array}{l}\text { Sala-Roca et al. } \\
\text { (2012) (Catalonia, } \\
\text { Spain) }\end{array}$ & $\begin{array}{l}13 \text { females and } 8 \text { males } \\
\text { aged } 19-28 \text { years }\end{array}$ & $\begin{array}{l}\text { Inductive content } \\
\text { analysis }\end{array}$ & $\begin{array}{l}\text { Themes around socialisation, } \\
\text { familial relationships, housing } \\
\text { and success }\end{array}$ & $\begin{array}{l}\text { Comparatively short interviews: } 30-45 \\
\text { minutes. Ethics not discussed }\end{array}$ \\
\hline $\begin{array}{l}\text { Samuels and } \\
\text { Pryce (2008) } \\
\text { (USA) }\end{array}$ & $\begin{array}{l}44 \text { participants } \\
\text { interviewed at } 17,19 \\
\text { and } 21 \text { years }\end{array}$ & $\begin{array}{l}\text { Interpretive } \\
\text { thematic analysis }\end{array}$ & $\begin{array}{l}\text { Themes around the competing } \\
\text { tensions of transition and } \\
\text { adulthood }\end{array}$ & $\begin{array}{l}\text { Backgrounds of researchers raised but } \\
\text { not discussed in relation to how their } \\
\text { perspectives on the data was affected or } \\
\text { what was done to address that }\end{array}$ \\
\hline $\begin{array}{l}\text { Samuels (2009) } \\
\text { (USA) }\end{array}$ & $\begin{array}{l}23 \text { participants who had } \\
\text { recently aged out of } \\
\text { foster care. } 20 \text { women } \\
\text { and nine men }\end{array}$ & $\begin{array}{l}\text { Constant } \\
\text { comparative } \\
\text { grounded theory }\end{array}$ & $\begin{array}{l}\text { Three themes surrounding } \\
\text { family and permanence }\end{array}$ & $\begin{array}{l}\text { Convenience sample used, all being } \\
\text { supported financially and practically. } \\
\text { Ethics not discussed }\end{array}$ \\
\hline
\end{tabular}


to the synthesis as the individual codes translated the constructs across the research papers reviewed. These codes gradually led to the development of descriptive themes inferring the meaning of the constructs within them, which eventually led to the emergence of analytical themes and superordinate themes (Thomas and Harden, 2008).

\section{Results}

Three themes emerged, which are described here. The ways in which the themes relate to one another is illustrated in Figure 1.

Theme 1. Navigation and resilience - an interrelated process

The first finding of the analysis indicated upward and downward spirals of success. Some storytellers described striving and building resilience and indeed Samuels and Pryce (2008) suggested, "Rather than accept or internalize negative stereotypes of foster children [...] youth constructed their life stories as testimonies of survival against all odds" (p. 1206). However, others contended with getting lost in the system and not developing key resiliencies. Setbacks such as being "kicked out" (Del Quest et al., 2012, p. 1609; Jones, 2011, p. 1926; Perez and Romo, 2011, p. 243) or multiple moves and losses as cited in all nine studies, led to depleted resilience. When resilience was diminished, so was the storyteller's ability to navigate their way successfully through the system.

1.1 Support and supporting. Successful navigation of the system appeared in many forms. For some, it was a case of developing a safety net or finding resources "[...] just take advantage of the situation that you're already in whatever you can get" (Samuels and Pryce, 2008, p. 1206). Some participants felt strongly about helping others (Hines et al., 2005) or only felt comfortable when providing for others (Samuels and Pryce, 2008). The low regard some participants had for the care they received appeared to reinforce these perceptions: "They didn't care" (Hyde and Kammerer, 2009, p. 260). There were also indications amongst the accounts that providing well for others was synonymous with being a responsible adult; and perhaps ultimately not repeating a cycle that had left the storytellers in care (Hines et al., 2005). A key struggle appeared to be
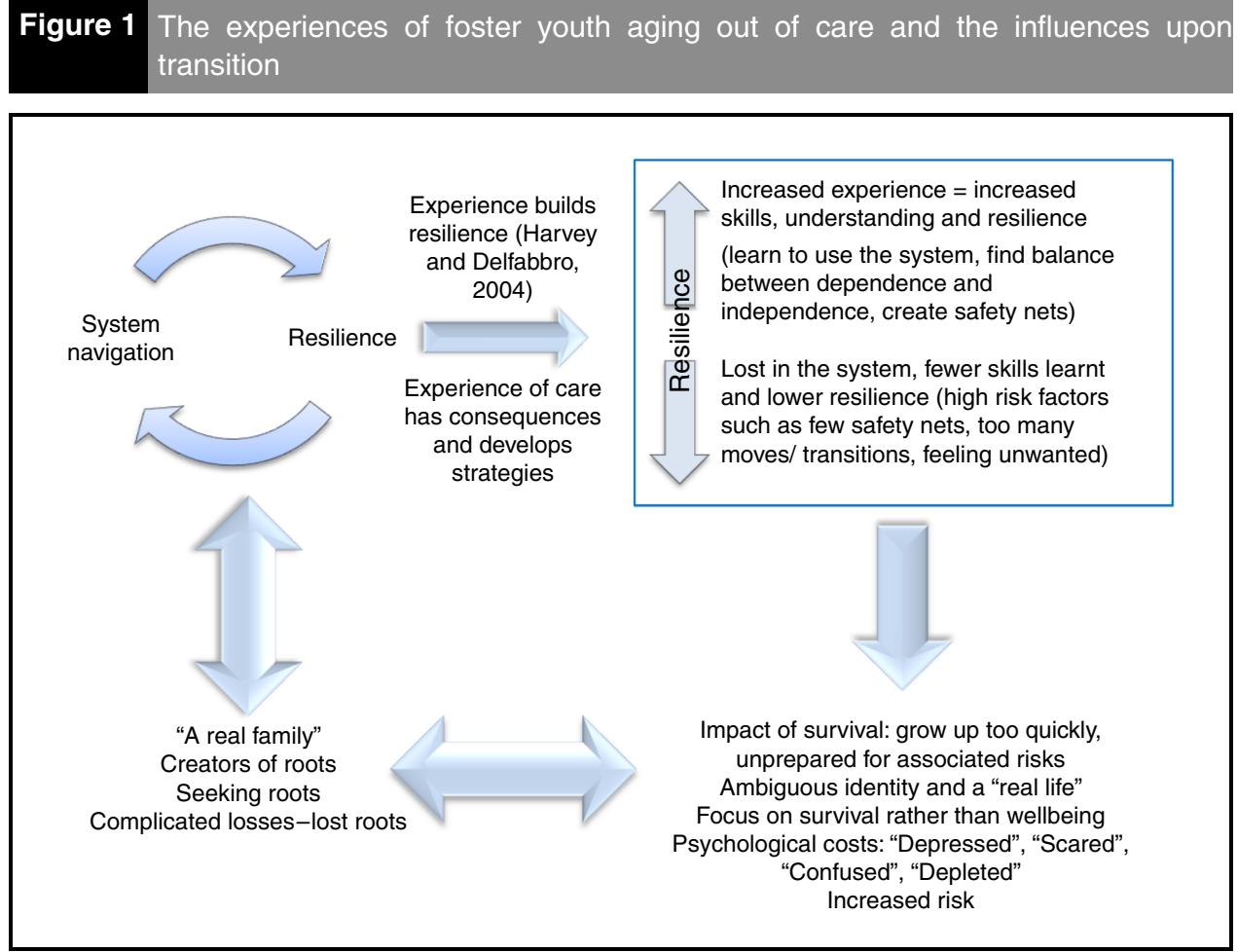
balancing independence and dependence, which if achieved could maintain global independence (Hines et al., 2005).

1.2 Strive to thrive. Work and study served as useful navigational tools for some who were able to use these resources to find a way out of their foster youth identity (Sala-Roca et al., 2012). Motivation and success however, came at a price (Del Quest et al., 2012; Hines et al., 2005): "I just don't settle, even if I'm happy now, I'm always working on my next goal" (Hines et al., 2005, p. 388). Even for those who worked hard, sometimes events outside of their control could affect their success such as "not having a support system" (Jones, 2011, p. 1925).

A strong narrative amongst the accounts was of a need to strive to survive within an irregular and unpredictable system (Del Quest et al., 2012; Hyde and Kammerer, 2009; Jones, 2011; Perez and Romo, 2011; Sala-Roca et al., 2012). Other common accounts were of feeling unprepared for transition (Del Quest et al., 2012), unsupported through transition and having little control over the unpredictability of their life-course (Hines et al., 2005; Jones, 2011; Del Quest et al., 2012).

1.3 Head over heart. The dangers of falling through the gap (Del Quest et al., 2012; Perez and Romo, 2011; Samuels and Pryce, 2008) and anxieties of an uncertain future (Del Quest et al., 2012; Hines et al., 2005; Hyde and Kammerer, 2009) appeared to create a sense of steely resilience and endurance. There were many examples of positive reframes: "I like my bumps and bruises" (Samuels and Pryce, 2008, p. 1205). Humour was also a key facet, even in the most distressing of situations (Del Quest et al., 2012; Hines et al., 2005; Hyde and Kammerer, 2009; Jones, 2011; Perez and Romo, 2011).

Theme 2. The psychological impact of survival

Care homes were one and the same with danger for several storytellers (Del Quest et al., 2012). One young man described the emotional impact of his care: "scared [...] It was very depressing" (Hyde and Kammerer, 2009, p. 270). This is perhaps further evidence of the continual stressors many experienced: "Much like the abusive homes from which many came, some of these environments required constant vigilance" (Hyde et al., p. 270).

Participants with extreme survivalist self-reliance perspectives (Samuels and Pryce, 2008) struggled to ask for help when they needed it. They were therefore increasingly vulnerable through the transition process: "In foster care you don't really have a sense of home [...] you have more a sense of survival [...]” (Samuels, 2009, p. 1233). This sense of survival appeared to cause numerous difficulties for young people when they emerged from care such as maintaining relationships, feeling satisfied with what they had achieved and securing a support network.

2.1 Too much too soon. Samuels and Pryce (2008) highlighted how the lack of a safety net in the form of nuclear family meant that participants had to adopt an emotional independence too advanced for their developmental stage: "I think some people are forced to grow up faster than they would like to. I think I was one of them [...]" (p. 1203). Some misconstrued this for self-sufficiency (Hines et al., 2005). Independent survivors described forfeiting care they were entitled to (Perez and Romo, 2011) and professing they did not require care. Therefore, they were not offered the help they needed (Samuels and Pryce, 2008) or desired (Samuels, 2009). This was underpinned by a wish to evidence independence in order to avoid being further let down by others (Samuels and Pryce, 2008).

Accordingly, the psychological impact of growing up too quickly was acknowledged: "They put you through too much, it seems like, for a young kid and then they expect you to be normal at 18" (Del Quest et al., 2012, p. 1610). The emotional hurdles of survival were clear in many of the stories told: "A lot more things are given to you raw" (Samuels, 2009, p. 1233), and detachment was often used as a defence (Hines et al., 2005; Hyde and Kammerer, 2009).

2.2 Identity and a "real life" (Samuels and Pryce, 2008, p. 1201). The identity struggles the storytellers faced as they experienced transition were complex and multidimensional. Common identities were of being disconnected, a victim, a survivor, being different, superior or a fighter (Del Quest et al., 2012; Hines et al., 2005; Hyde and Kammerer, 2009). Becoming a quick learner and chameleon-like in how they approached their social identity seemed necessary. 
"I didn't know any other way and I just decided that I'm going to pretend that I'm not me" (Hines et al., 2005, p. 389).

Normality as a luxury was also mentioned in several accounts: "It's a privilege to grow up how you suppose to" (Samuels and Pryce, 2008, p. 1203). A desire for normality in the eyes of others led some to hide their circumstances: "Nobody knew I was in the foster care system" (Hines et al., 2005, p. 385). However, some expressed a sense of superiority: "all my life as a kid I looked down at people my age [...]. I always felt more advanced" (Hines et al., p. 385). Others appeared to turn normality around, establishing an alternative reality in which they were the norm having: "earned the real life" (Samuels and Pryce, 2008, p. 1206).

Theme 3. Complex relationships - growing, nurturing and keeping new roots in old and new soil

3.1 "A real family" (Samuels, 2009, p. 1233). Despite the participants' fractured early relationships, many had a clear idea of what family meant: "you can just feel real comfortable and welcome [...] no matter what you do, they know you" (Samuels, 2009, p. 1233). Amongst the accounts there was a consistency between family, home and belonging (Samuels, 2009). Where this consistency was not found, relationships were more difficult: "I don't see them as my real family" (Del Quest et al., 2012, p. 1612).

Biehal and Wade (1996) suggested that even when participants were able to reconnect to their families after transition, the initial rejection still affected their emotional adjustment to their new identity: "Just because you belong to someone doesn't mean they're gonna care for you" (Samuels, 2009, p. 1234). Others who had found alternative families such as in a gang, struggled to find a different family even if they felt they would benefit (Del Quest et al., 2012).

Within the stories of emotionally successful foster placements, experiencing love and explicit familial ties were mentioned much more often (Hyde and Kammerer, 2009; Samuels, 2009). "You know, the foster family, they showed a lot of love and outside of mother, father, brother, you know like the grandparents [...]" (Hines et al., 2005, p. 389).

3.2 Creators of roots. Through transition some participants managed to maintain contact and seek support from their foster mothers (Del Quest et al., 2012), their service providers and biological parents (Jones, 2011) or other social networks (Hines et al., 2005): "You know. I had nowhere to go, and was taking drugs [...] and this boy helped me to move away from bad friends [...]" (Sala-Roca et al., 2012, p. 1019). Friendship offered practical solutions as well as emotional roots: "You meet a person who offers you to stay with them and you're like, OK, I don't have nowhere else to go, so might as well just go with you" (Perez and Romo, 2011, p. 243). However, dependence left some participants isolated and without other key support networks and consequently vulnerable to abuse (Sala-Roca et al., 2012).

3.3 Seeking roots. Seeking roots with parents and extended family was a key feature to many of the accounts. For some, transition seemed to suggest a move away from foster parents towards biological parents, in spite of the cause of their move to foster care originally: "You want to be with your real family [...] your foster parents should be glad that you are leaving [...]" (Samuels, 2009, p. 1235). For others, transition simply provided a way home: "where I am supposed to be" (Samuels, 2009, p. 1235).

Some storytellers made reference to how the system had hindered their opportunities to seek their biological roots, sometimes with little explanation as to why (Samuels, 2009). The disconnection that some participants felt towards their biological families was sometimes difficult to overcome: "It just felt weird, you know, your mum coming to see you and not knowing what to say to her after so long being with her" (Biehal and Wade, 1996, p. 431). However, for some seeking biological roots led to positive and supportive relationships symbolic of what so many participants describe as a real family, "When me mam started visiting me in nick (prison). I knew then, I didn't feel lonely then. From then on I knew me mam, she'd always be there for me" (Biehal and Wade, 1996, p. 430).

3.4 Complicated losses - lost roots. The complex nature of the losses experienced is mirrored in the complexity of the participants' emotional responses which left "some [participants] to blame themselves for the abuse or rejection they had suffered and left them confused about 
relationships in general" (Biehal and Wade, 1996, p. 434). A number of accounts detailed how established roots with foster parents had eventually been lost. Additionally, one young woman described how she rejected the offer of adoption due to her fears she would experience painful loss again (Samuels, 2009). Consequently, grief and grieving appeared through many stories: grief of what should have been (Samuels, 2009); missed opportunities for grieving exacerbating distress (Perez and Romo, 2011); and grief because "They were becoming my family. But then I would always get drugged [dragged] right out of them" (Samuels, 2009, p. 1233).

\section{Discussion}

The findings of the synthesis both support and advance existing research in the field of the psychological impact of transition. Following the example of Stein (2006), the following discussion of the results and recommendations for clinical practice are structured in line with the three theories to which the themes found relate: resilience, focal theory and attachment.

\section{Resilience and coping}

As children in foster care are known to be at an increased risk of mental illness (Golding, 2003; Mullan et al., 2007), understanding resilience in relation to this group is essential. Data from this synthesis suggested that coping with transition was increased where there was a key person to rely on. It was important that someone trusted could be approached for help, support resource building and provide education about the wider systems. In the UK, this vital role often falls to the personal advisor (PA, Children Leaving Care Act, 2000). The role of the PA is to "develop Pathways Plans with care leavers, to meet their support needs and help them prepare for independent living" (NCAS, 2008, p. 4). This support should continue until the young person is aged 21, or 25 if remaining in some form of education. Although many of the PA job descriptions highlight the counselling elements of the job alongside the understandably more pressing financial and accommodation issues, psychological training is not a direct requirement for the post.

Within psychological supervision the therapeutic relationship, threats to that relationship, the role of prior attachments and the wellbeing of the therapist form the basis of regular conversations. Difficult attachment histories are particularly relevant for this client group. Perhaps supervision with the PA's wellbeing at the forefront is an area in which psychologists could support this potentially pivotal role. This additional support may be particularly necessary if the young person wishes to return home to their birth family due to ongoing safeguarding and attachment difficulties, which may cause additional pressures for the PA (NSPCC, 2014). It would be helpful to explore the experiences of young people's working relationships with PAs to see what relational issues are present. One might anticipate many therapeutic aspects to the relationship such as developing a secure base for a successful alliance (Eames and Roth, 2000), ruptures (Safran et al., 2001) and the need for positive endings (Davis, 2008). Additionally, brief forms of therapy such as solutions focused practices may serve as a helpful addition to continued professional development.

Young adults still require therapeutic services as much as they did whilst in care but are seldom able to access them (Courtney et al., 2001). Schneidermana et al. (2012) found that care workers could be helpful advocates and companions in the process of seeking care. The present meta-synthesis found that many young people wanted more support from their carers (Hines et al., 2005; Hyde and Kammerer, 2009). The importance of a PA is again highlighted here in order for a young person to feel supported through transition and prevent the re-experiencing of past attachment traumas.

Trauma often precedes moves into care (Cook et al., 2005; Lieberman et al., 2011). The current synthesis emphasised that many traumas exist within the care system also. Loss, danger, abuse and loneliness were all mentioned; as were descriptions of on-going anxiety, anger, uncertainty and detachment (Hines et al., 2005; Hyde and Kammerer, 2009). Karoly and Rhuehlman (2006) suggest resilience incorporates coping but also neurological and interpersonal elements. They discuss a "health-despite-adversity" model (p. 90). They suggest that resilience can "allow persons [...] to navigate towards their goals in a hopeful, positive and efficacious manner" 
(p. 96). This research suggests fostering hope may be a key role in the interrelated process of navigating the system and developing resilience as discussed in the first theme of this review.

Fostering hope in young adults transitioning out of care would seem an important role for psychologists. Therapeutic work around acceptance and grief (Jones and LaLiberte, 2012) might also address some of the distress young people experience, especially some of the secondary losses encountered when relationships with birth parents break down again even after leaving care. Cultural loss and separation formed an element of Perez and Romo's (2011) findings and it would be helpful in the development of UK services if more was known about how ethnic minorities in the UK experience transition. Elements of difference might be particularly important amongst minority groups.

Also present in the first theme were reflections on the importance of education for both practical and emotional reasons. Education could provide a source of income and stability but also an alternative identity to a "foster youth" identity and a platform to reflect upon difficult emotional experiences within a new support system.

Identity as a care leaver and difference from peers was found to be a key element in the current synthesis, which could foster a sense of superiority, determination and resilience. This supports the findings of Herrenkohl et al. (1994) who suggest that "determination to be different" (p. 301) endorses resilience. Some participants remarked how their successes were exceptions, suggesting they held a negative stereotype of foster youth and were surprised they could escape its trappings.

\section{The focal model of adolescence and transition}

This section discusses the relevant themes found in relation to the focal model of adolescence (Coleman and Hendry, 1999) which describes how young people can struggle when they have multiple challenges to face (Stein, 2006). The focal theory of adolescence suggests that we tend to navigate multiple challenges through adolescence well when we can focus on one issue at a time (Coleman, 1989). However, for young people leaving care attempting to cope with multiple moves, a lack of stability, stigma associated with being in care, and losing important people culminated in multiple contemporaneous challenges. Many of the participants who described successful stories managed to focus on one area of their life or form meaningful attachments to one or two people.

However, when transitional support was available it was often ill-timed or too sparse (Perez and Romo, 2011). Providing support at an appropriate time in relation to sequential rather than cumulative challenges could prevent young people feeling overwhelmed and enhance their chances of success. The review illustrated how the storytellers had to manage multiple challenges simultaneously, and often with little support (Del Quest et al., 2012; Hyde and Kammerer, 2009). Healing and transition were both processes often out of sync with each other, even though they occurred simultaneously and had immense reciprocal impacts.

In order to provide young people with a better chance of successfully adjusting to transitions, practitioners must find ways to reduce multiple challenges appearing at any one time. Support provided at appropriate points could support learning and experience through transitions (Perez and Romo, 2011), which if managed well by the young person could enhance their confidence and resilience in further transitions. Support in relation to housing, financial management and life skills provided at the relevant times for the young person (Stein, 1997) can help them develop practical skills and emotional resilience, key components to successful transition (Gilligan, 2000). These particular findings explain why the recommendations of Stein (1997) and Hayes (2013) are so important.

\section{Attachment and relationships}

A significant code that arose through the analysis was that of being fiercely self-reliant and detaching from services and people. This could be viewed as a result of disorganised attachment styles formed through early relationships. This relational perspective is relevant to themes two and three in particular. Disorganised attachment styles are understandably common 
amongst young people who have had turbulent relationship histories throughout their childhood. Jacobs et al. (2012) found that self-reliance was an enduring effect of disorganised attachment styles for young people in care, even following attachment informed support programmes.

Relating loss and rejection to attachment literature, one might consider whether the attachment response of being insecure yet self-reliant (Hines et al. , 2005; Perez and Romo, 2011; Samuels, 2009; Samuels and Pryce, 2008) towards an uncertain care system may account for the difficulties found by some participants to ask for help or take support offered to them (Downes, 1992). Golding (2003) describes how young people who have experienced rejection themselves can often elicit further rejection in their future relationships too. This further supports the need for foster carers to help young people understand attachment difficulties, which may reduce the breakdown of some placements (Stovall-McClough and Dozier, 2004).

Within the context of loss, despite recommendations that siblings should be kept together when possible (Children Act, 1989), the synthesis highlighted examples where siblings were not kept together. This could impact further upon the uncertainty participants hold about their identity (Bilson and Barker, 1992/1993). Those who described meaningful attachments to key figures and shared an identity with a family as well as being a foster youth described more positive experiences of transition.

Trans-generational patterns of behaviour, attempts to correct past mistakes and how this knowledge can help a child understand where anger for example may be coming from have more recently been considered (Dallos et al. , 2010; Kincaid and Wolpow, 2010). Clear examples of where such practices could be invaluable are evidenced in this review (Biehal and Wade, 1996; Perez and Romo, 2011). Golding (2003) writes of how the consultation model she developed for foster carers helped carers feel less victimised by the behaviour they saw in the child as they understood they were witnessing a reaction to the child's past relationships and not their own relationship with the child. If potential attachment patterns and repercussions can be presented to children's families as a part of an early intervention, this understanding may also prevent placements failing unnecessarily.

Golding (2010) suggests that the emotional impact of working with traumatised children can lead to "splits, disagreements and even rivalries to develop both within and between services" (p. 583). Conway (2009, cited in Golding, 2010) identified that this discord between services can sometimes lead to preventable placement breakdowns. This underlines again the systemic implications of work with looked after children and the need for psychological services to offer systemically informed therapies to colleagues, carers and the young people themselves (Appleyard and Osofsky, 2003). Further research in this area might explore the possible relationship between existing attachment schemas and the struggle for independent dependence that was found in this review.

Carers have reported they feel more supported as a result of psychological guidance, especially if this is followed by a therapeutic intervention (Golding, 2004). Post-trauma cognitivebehavioural therapy has been found to be particularly helpful for children who have been traumatised in their early years (Cohen et al., 2012; Landsverk et al., 2006) and is therefore another area of possible effectiveness in this field.

When designing an individual intervention for a looked after child it is important to bear in mind the attachment difficulties the child may have (Golding, 2003). The clinician must therefore consider any potential threat of the therapeutic alliance to the child's existing attachments (Hart and Thomas, 2008). A safe place for the young person and carer to practice positive communication and interpersonal connectedness within therapy could be essential to managing their attachment patterns (Gill, 2010). Additionally, mental health services could be delivered within a child's immediate network rather than in isolated mental health services (Landsverk et al., 2006), which may address some of the systemic issues raised in this discussion.

To take this a step further, Hughes (2004) described how a therapeutic alliance of empathy, boundaries and acceptance can be established between the young person and their carer in 
therapy to nurture their attachment and address underlying difficulties. The likely characteristics of children who have histories of trauma, neglect and broken attachments (Bowlby, 1973) will also be crucial in therapy as discussed in this section.

\section{Limitations}

Although this synthesis adds a depth to the understanding of the experience of transition, there remain some limitations in terms of how representative the narratives are to the majority of young people who transition through care in the UK. Although there are many cross-cultural themes throughout this synthesis such as relationship difficulties and obstacles to education, this synthesis predominantly reviewed US studies due to their availability. Additionally, those who took part in the studies reviewed were often receiving additional educational or financial support. The majority of studies had primarily female participants. The studies presented only a snapshot of transition over a fairly short period of time. Even a period of three to four years is a relatively short amount of time to adjust to the impacts of transition. Longitudinal research is the obvious next step. Finally, research conducted to date represents minimal cultural diversity. By exploring within and between cultural experiences of transition, we can learn from those stories and develop systems led by those who live them. This process appears particularly relevant as children from "minority ethnic groups appear to be overrepresented in the looked after population" (Harker, 2012, p. 2).

\section{Conclusion}

The current review highlighted many of the well-known challenges young people face when transitioning from care and explored the psychological impact of these encounters. The findings illustrated the unpredictability of the system and that many young people have to cope with too much too soon. This affected their ability to develop resilience, which in turn affected their sense of identity and capacity to navigate their transition.

Therefore, there are two vital recommendations from this research. First, a well informed and consistent attachment figure must be provided. This person needs to afford a secure base from which the young person can develop the seemingly illusive independent dependence from the care system that seems so crucial in navigating transition. Fostering hope and nurturing resilience through direct and indirect work with the young person and their system are key roles for mental health services. Second, there is a need to reduce the number of challenges a young person is expected to cope with at once. With well-planned pathways, this is feasible. However, when multiple challenges for the young person arise unexpectedly, services need to respond in a united way to work with the practical and emotional issues. If managed well, this would promote the interrelated effect of resilience and positive navigation found in this review. The young person would experience another positive step through their transition and as a result become better prepared for the next hurdle. Finally, this review also highlighted again the importance of attachment and discussed why attachment theory needs to underpin all efforts made by services.

\section{Summary of implications for policy and practice}

- Identity as a care leaver and difference from peers could foster a sense of superiority, determination and resilience.

- Fostering hope in young adults transitioning out of care would seem an important role for psychologists.

- Therapeutic work around acceptance and grief (Jones and LaLiberte, 2012) might also address some of the distress young people experience, especially some of the secondary losses. 


\section{References}

References marked with an asterisk are the studies included in the meta-synthesis.

Appleyard, K. and Osofsky, J.D. (2003), "Parenting after trauma: supporting parents and caregivers in the treatment of children impacted by violence", Infant Mental Health Journal, Vol. 24 No. 2, pp. 111-25.

*Biehal, N. and Wade, J. (1996), "Looking back, looking forward: care leavers, families and change", Children and Youth Services Review, Vol. 18 Nos 4/5, pp. 425-45.

Biehal, N., Dixon, J., Parry, E., Sinclair, I., Green, J., Roberts, C., Kay, C., Rothwell, J., Kapadia, D. and Roby, A. (2012), "The care placements evaluation (CaPE) evaluation of multidimensional treatment foster care for adolescents (MTFC-A)”, Research Brief No. DFE-RB194, Department for Education, London, available at: www.york.ac.uk/inst/spru/research/pdf/cape.pdf

Bilson, A. and Barker, R. (1992/1993), "Siblings of children in care or accommodation: a neglected area of practice”, Practice, Vol. 6 No. 4, pp. 307-18.

Blades, R., Hart, D., Lea, J. and Willmott, N. (2011), Care - A Stepping Stone to Custody? The Views of Children in Care on the Links Between Care, Offending and Custody, ISBN 978-1-908504-99-9 Prison Reform Trust. First published in 2011 by Prison Reform Trust, London, available at: www.prisonreformtrust. org.uk/Portals/O/Documents/careasteppingstonetocustody.pdf (accessed 9 November 2014).

Bowlby, J. (1973), Separation: Anxiety and Anger. Attachment and Loss Nol. 2); (International PsychoAnalytical Library No.95), ISBN 0-7126-6621-4, Hogarth Press, London.

Children Act (1989), "London: her majesty's stationery office”, available at: www.legislation.gov.uk/ukpga/ 1989/41

Children Leaving Care Act (2000), "Printed in the UK by the stationery office limited under the authority and superintendence of Carol Tullo", Controller of Her Majesty's Stationery Office and Queen's Printer of Acts of Parliament, available at: www.educationengland.org.uk/documents/pdfs/2000-children-leaving-care-act.pdf

Cohen, J.A., Mannarino, A.P., Kliethermes, M. and Murray, L.A. (2012), "Trauma-focused CBT for youth with complex trauma”, Child Abuse and Neglect, Vol. 36 No. 6, pp. 528-41.

Coleman, J.C. (1989), "The focal theory of adolescence: a psychological perspective", in Hurrelmann, K. and Engel, U. (Eds), The Social World of Adolescents, Walter de Gruyter, Berlin, pp. 43-56.

Coleman, J.C. and Hendry, L. (1999), The Nature of Adolescence, ISBN 0416726305, Routledge, London.

Collin-Vézina, D., Coleman, K., Milne, L., Sell, J. and Daigneault, I. (2011), "Trauma experiences, maltreatment-related impairments, and resilience among child welfare youth in residential care", International Journal of Mental Health and Addiction, Vol. 9 No. 5, pp. 577-89.

Conway, P. (2009), "Falling between minds: the effects of unbearable experiences on multi-agency communication in the care system", Adoption and Fostering, Vol. 33 No. 1, pp. 18-29.

Cook, A., Spinazzola, J., Ford, J., Lanktree, C., Blaustein, M., Cloitre, M., DeRosa, R., Hubbard, R., Kagan, R., Liautaud, J., Mallah, K., Olafson, E. and Van der Kolk, B. (2005), "Complex trauma in children and adolescents", Psychiatric Annals, Vol. 35 No. 5, pp. 390-8.

Courtney, M.E., Piliavin, I., Grogan-Kaylor, A. and Nesmith, A. (2001), "Foster youth transitions to adulthood: a longitudinal view of youth leaving care”, Child Welfare Leaque of America, Vol. 80 No. 6, pp. 685-717.

Critical Appraisal Skills Programme (2010), "Making sense of evidence about clinical effectiveness. Qualitative research", available at: www.sph.nhs.uk/sph-files/casp-appraisal-tools/Qualitative Appraisal Tool.pdf

Dallos, R., Denman, K., Stemon, J. and Smart, C. (2010), "The construction of ADHA: family dynamics, conversations and attachment patterns", Human Systems: The Journal of Therapy, Consultation and Training, Vol. 23 No. 1, pp. 5-26.

Davis, D.D. (2008), Terminating Therapy: A Professional Guide to Ending on a Positive Note, ISBN 9780470105566, Wiley, Hoboken, NJ.

*Del Quest, A.D., Fullerton, A., Geenen, S. and Powers, L. (2012), "The research consortium to increase the success of youth in foster care", Children and Youth Services Review, Vol. 34 No. 9, pp. 1604-15.

Department of Health (2007), "Transition: getting it right for young people: improving the transition of young people with long term conditions)", available at: www.dh.gov.uk/en/Publicationsandstatistics/Publications/ PublicationsPolicyAndGuidance/DH_4132145 
Dima, G. and Skehill, C. (2011), "Making sense of leaving care: the contribution of Bridges model of transition to understanding the psycho-social process", Children and Youth Services Review, Vol. 33 No. 12, pp. 2532-9.

Dixon-Woods, M., Bonas, S., Booth, A., Jones, D., Miller, T., Sutton, A., Shaw, R., Smith, J. and Young, B. (2006), "How can systematic reviews incorporate qualitative research? A critical perspective", Qualitative Research, Vol. 6 No. 1, pp. 27-44.

Downes, C. (1992), Separation Revisited, Aldershot, Ashgate, cited in Dima and Skehill (2011), "Making sense of leaving care: the contribution of Bridges model of transition to understanding the psycho-social process", Children and Youth Services Review, Vol. 33 No. 12, pp. 2532-39, doi:10.1016/j.agee. 2009.08.011.

Eames, V. and Roth, A. (2000), "Patient attachment orientation and the early working alliance: a study of patient and therapist reports of alliance quality and ruptures", Psychotherapy Research, Vol. 10 No. 4, pp. 421-34.

Erwin, E.J., Brotherson, M.J. and Summers, J. (2011), "Understanding qualitative meta-synthesis. Issues and opportunities in early childhood intervention research", Journal of Early Intervention, Vol. 33 No. 3, pp. 186-200.

Gill, S. (2010), "The therapist as psychobiological regulator: dissociation, affect attunement and clinical process", Clinical Social Work Journal, Vol. 38 No. 3, pp. 260-8.

Gilligan, R. (2000), "Adversity, resilience and young people: the protective value of positive school and spare time experiences”, Children and Society, Vol. 14 No. 1, pp. 37-47.

Golding, K. (2003), "Helping foster carers, helping children: using attachment theory to guide practice", Adoption and Fostering Journal, Vol. 27 No. 2, pp. 64-73.

Golding, K. (2004), "Providing specialist psychological support to foster carers: a consultation model", $\underline{\text { Child }}$ and Adolescent Mental Health, Vol. 9 No. 2, pp. 71-6.

Golding, K.S. (2010), "Multi-agency and specialist working to meet the mental health needs of children in care and adopted", Clinical Child Psychologv and Psychiatry, Vol. 15 No. 4, pp. 573-87.

Gomersall, T., Madill, A. and Summers, L.K. (2011), "A metasynthesis of the self-management of Type 2 diabetes", Qualitative Health Research, Vol. 21 No. 6, pp. 853-71.

Harker, R. (2012), "Children in Care in England: Statistics. Social and General Statistics", available at: www. parliament.uk/briefing-papers/SN04470

Hart, J. and Thomas, A. (2008), "Methods for the thematic synthesis of qualitative research in systematic reviews", BMC Medical Research Methodology, Vol. 8 No. 1, p. 45.

Harvey, J. and Delfabbro, P.H. (2004), "Psychological resilience in disadvantaged youth: a critical overview", Australian Psychologist, Vol. 39 No. 1, pp. 3-13.

Hayes, J. (2013), "An exploratory study into care leavers transition to adulthood", Critical Social Thinking: Policy and Practice, Vol. 5, pp. 132-49, available at: www.ucc.ie/en/media/academic/appliedsocialstudies/ docs/JoanneHayes.pdf; www.ucc.ie/en/appsoc/resconf/conf/cst/vol5/

Herrenkohl, E.C., Herrenkohl, R.C. and Egolf, B. (1994), "Resilient early school-age children from maltreating homes: outcomes in late adolescence", American Journal of Orthopsychiatry, Vol. 64 No. 2, pp. 301-9.

*Hines, A.M., Merdinger, J. and Wyatt, P. (2005), "Former foster youth attending college: resilience and the transition to young adulthood", American Journal of Orthopsychiatry, Vol. 75 No. 3, pp. 381-94.

Hodges, N. (2011), "Qualitative research: a discussion of frequently articulated qualms (FAQs)", Family and Consumer Sciences Research Journal, Vol. 40 No. 1, pp. 90-2.

Hughes, D. (2004), "An attachment-based treatment of maltreated children and young people", Attachment and Human Development, Vol. 6 No. 3, pp. 263-78.

*Hyde, J. and Kammerer, N. (2009), "Adolescents' perspectives on placement moves and congregate settings: complex and cumulative instabilities in out-of-home care", Children and Youth Services Review, Vol. 31 No. 2, pp. 265-73.

Jackson, S. and Cameron, C. (2012), "Continuing educational participation among children in care in five countries: some issues of social class", Journal of Education Policy, Vol. 27 No. 3, pp. 387-99. 
Jackson, S. and MacParlin, P. (2006), "The education of children in care", The Psychologist, Vol. 19 No. 2, pp. 90-3, available at: www.thepsychologist.org.uk/archive/archive_home.cfm?volumelD=19 \&edition $\mid \mathrm{D}=132 \&$ ArticlelD $=986$

Jackson, S. and Simon, A. (2005), "The costs and benefits of educating children in care", in Chase, E., Simon, A. and Jackson, S. (Eds), In Care and After: A Positive Perspective, Routledge, London.

Jacobs, C., llan-Clarke, Y. and Bifulco, A. (2012), "The use of the attachment style interview. Caring about attachment”, Lifespan Research Group, Centre for Abuse and Trauma Studies, Kingston University London, available at: www.ccinform.co.uk/articles/2012/03/05/6604/caring + about + attachment + in + young + people + in + residential + care + the + use + of + the + attachment + style.html

*Jones, L. (2011), "The first three years after foster care: a longitudinal look at the adaptation of 16 youth to emerging adulthood”, Children and Youth Services Review, Vol. 33 No. 10, pp. 1919-29.

Jones, L. and LaLiberte, T. (2012), "Supporting reunification and preventing re-entry into out-of-home care", Child Welfare Information Gateway, available at: www.childwelfare.gov/pubs/issue_briefs/srpr.pdf

Karoly, P. and Rhuehlman, L.S. (2006), "Psychological 'resilience' and its correlates in chronic pain: findings from a national community sample", International Association for the Study of Pain, Vol. 123 Nos 1/2, pp. 90-7.

Kincaid, S. and Wolpow, R. (2010), "Kindness, kith, kin, compassion, and community: a response model connecting human services and education to address trauma", Human Services Today, Vol. 7 No. 1, pp. 1-13, available at: http://hst.coehs.uwosh.edu/Fall2010articles/KincaidWolpowF10.pdf

Landsverk, J.A., Burns, B.J., Stambaugh, L.F. and Rolls Ruetz, J.A. (2006), "Mental health care for children and adolescents in foster care: review of research literature", Casey Family Programs, pp. 1-114, available at: www.casey.org/Resources/Publications/pdf/MentalHealthCareChildren.pdf

Layne, C.M., Warren, J., Shalev, A. and Watson, P. (2007), "Risk, vulnerability, resistance, and resilience: towards an integrative conceptualization of posttraumatic adaptation”, in Friedman, M.J., Kean, T.M. and Resick, P.A. (Eds), PTSD: Science and Practice: A Comprehensive Handbook, Guilford Press, New York, NJ, pp. 497-520.

Lewis, R., Donaldson-Feilder, E. and Pangallo, A. (2011), "Developing resilience", Chartered Institute of Personnel and Development, available at: www.cipd.co.uk/binaries/5490\%20Developing\%20 Resilience\%20RI\%20(WEB).pdf

Lieberman, A.F., Chu, A., Van Horn, P. and Harris, W.W. (2011), "Trauma in early childhood: empirical evidence and clinical implications", Development and Psychopathologv Vol. 23 No. 2, pp. 397-410.

Mullan, C., McAlister, S., Rollock, F. and Fitzsimons, L. (2007), “'Care just changes your life': factors impacting upon the mental health of children and young people with experiences of care in Northern Ireland", Child Care in Practice, Vol. 13 No. 4, pp. 417-34.

NCAS (2008), "Introduction to leaving care", available at: http://resources.leavingcare.org/uploads/ bcbf561a91a1dfa19fa1ad499e04cd47.pdf

NICE (2010), "Looked-after children and young people (PH28)", NICE Guidance, October, available at: www.nice.org.uk/PH28

NSPCC (2014), "How many children are looked after in the UK?", NSPCC Statistics on Looked after Children, April, available at: www.nspcc.org.uk/Inform/resourcesforprofessionals/lookedafterchildren/ statistics_wda88009.html

*Perez, B.F. and Romo, H.D. (2011), “'Couch surfing' of Latino foster care alumni: reliance on peers as social capital”, Journal of Adolescence, Vol. 34 No. 2, pp. 239-48.

Safran, J.D., Muran, J.C., Samstag, L.W. and Stevens, C.L. (2001), "Repairing alliance ruptures", Psychotherapv: Theory, Research, Practice, Training, Vol. 38 No. 4, pp. 406-12.

*Sala-Roca, J., Biarnés, A.V., García, M.J. and Sabates, L.A. (2012), "Socialization process and social support networks of out-of-care youngsters", Children and Youth Services Review, Vol. 34 No. 5, pp. 1015-23.

*Samuels, G.M. (2009), "Ambiguous loss of home: The experience of familial (im)permanence among young adults with foster care backgrounds", Children and Youth Services Review, Vol. 31 No. 12, pp. 1229-39. 
*Samuels, G.M. and Pryce, J.M. (2008), “'What doesn't kill you makes you stronger': survivalist self-reliance as resilience and risk among young adults aging out of foster care", Children and Youth Services Review, Vol. 30 No. 6, pp. 1198-210.

Schneidermana, J.U., Smith, C. and Palinkasa, L.A. (2012), "The caregiver as gatekeeper for accessing health care for children in foster care: a qualitative study of kinship and unrelated caregivers", Children and Youth Services Review, Vol. 34 No. 10, pp. 2123-30.

Schofield, G. and Beek, M. (2005), "Providing a secure base: parenting children in long-term foster family care", Attachment and Human Development, Vol. 7 No. 1, pp. 3-25.

Spencer, R., Collins, M.E., Ward, R. and Smashaya, S. (2010), "Mentoring for young people leaving foster care: promise and potential pitfalls", Social Work, Vol. 55 No. 3, pp. 225-34.

Stein, M. (1997), What Works in Leaving Care? - Summary, Barnardo's, Essex, available at: www.barnardos. org.uk/wwlcare.pdf

Stein, M. (2006), "Young people aging out of care: the poverty of theory", Children and Youth Services Review, Vol. 28 No. 4, pp. 422-34.

Stone, S. (2007), "Child maltreatment, out-of-home placement and academic vulnerability: a fifteen-year review of evidence and future directions", Children and Youth Services Review, Vol. 29 No. 2, pp. 139-61.

Stovall-McClough, K.C. and Dozier, M. (2004), "Forming attachments in foster care: infant attachment behaviors during the first 2 months of placement", Development and Psychopathology, Vol. 16, pp. 253-71, doi:10.10170S0954579404044505.

The Who Cares Trust (2012), "Leaving Care", available at: www.thewhocarestrust.org.uk/

Thomas, J. and Harden, A. (2008), "Methods for the thematic synthesis of qualitative research in systematic reviews", BMC Medical Research Methodologv, Vol. 8 No. 1, pp. 45-55.

Tyler, K.A. (2006), "A qualitative study of early family histories and transitions of homeless youth", Journal of Interpersonal Violence, Vol. 21 No. 10, pp. 1385-93.

Walsh, W.A., Dawson, J. and Mattingly, M.J. (2010), "How are we measuring resilience following childhood maltreatment? Is the research adequate and consistent? What is the impact on research, practice, and policy?", Trauma Violence Abuse, Vol. 11 No. 1, pp. 27-41.

Windle, M. (1999), "Critical conceptual and measurement issues in the study of resilience", in Glantz, M.D.E.J. and Jeannette, L. (Eds), Resilience and Development, Positive Life Adaptations, p. 303.

\section{Appendix}

\section{Table Al Literature search strategy}

Search term (in subject)

Results

Resilience AND qualitative

Resilience AND trauma

Resilience AND trauma AND qualitative

Resilience AND Psychological maltreatment OR qualitative OR leaving foster care

Resilience AND leaving foster care OR qualitative

Foster care AND transition or leave AND qualitative AND resilience

Review AND leaving care

Leaving child services AND qualitative

Title only: review and leaving care

Title only: foster care AND qualitative

Title only: residential care AND qualitative

Total found

Duplicates removed

Inclusion/exclusion applied

Additional papers found manually

Total selected 
About the authors

Sarah Parry is currently completing a Doctorate in Clinical Psychology at the Lancaster University. Prior to clinical training, Sarah Parry directed an organisation that supported young people with additional needs in state care in Eastern Europe through practical resources, volunteer support and training. Sarah Parry is the corresponding author and can be contacted at: parrys1@exchange.lancs.ac.uk

Dr Stephen Weatherhead is a Lecturer in Research Methods, and a Clinical Tutor with the Lancaster University Doctorate in Clinical Psychology programme. Teaching responsibilities reflect clinical experience in neuropsychological assessment and therapy, culture and narrative. Research lecturing includes qualitative methodologies (particularly Narrative Analysis). Other responsibilities include research supervision and pastoral tutoring of trainee clinical psychologists. 